\title{
In Silico Modelling, Regulation of Cell Viability and Anti Atherosclerotic Effect in Macrophage by Decaffeinated Coffee and Green Tea Extract
}

\author{
Ermin Rachmawati ${ }^{1,2 *}$, M Saifur Rohman ${ }^{3}$, Lintang Widya Sishartami ${ }^{4}$, Djanggan Sargowo ${ }^{3}$, Umi Kalsum ${ }^{5}$
}

\section{Ermin Rachmawati ${ }^{1,2, *}, \mathrm{M}$ \\ Saifur Rohman ${ }^{3}$, Lintang Widya \\ Sishartami ${ }^{4}$, Djanggan Sargowo ${ }^{3}$ Umi Kalsum $^{5}$}

'Doctoral Program of Medical Science, Faculty of Medicine, Universitas Brawijaya, Malang, INDONESIA.

${ }^{2}$ Department of Biomedical Sciences,

Faculty of Medicine and Health Sciences UIN

Maulana Malik Ibrahim Malang, Malang, INDONESIA.

${ }^{3}$ Department of Cardiology and Vascular Medicine, Faculty of Medicine, Universitas Brawijaya, Malang, INDONESIA.

${ }^{4}$ Master Program in Biomedical Sciences,

Faculty of Medicine, Universitas Brawijaya, Malang, INDONESIA.

${ }^{5}$ Department of Pharmacology, Faculty of Medicine, Universitas Brawijaya, Malang INDONESIA.

\section{Correspondence}

\section{Ermin Rachmawati}

Doctoral Program of Medical Science, Faculty of Medicine, Universitas Brawijaya; Department of Biomedical Sciences,

Faculty of Medicine and Health Sciences UIN Maulana Malik Ibrahim Malang, Malang, INDONESIA.

E-mail: ermin.rachmawati@kedokteran. uin-malang.ac.id

History

- Submission Date: 20-11-2021;

- Review completed: 02-12-2021;

- Accepted Date: 15-12-2021.

DOI : 10.5530/pj.2022.14.7

Article Available online http://www.phcogj.com/v14/i1

\section{Copyright}

(C) 2022 Phcogj.Com. This is an openaccess article distributed under the terms of the Creative Commons Attribution 4.0 International license.

\begin{abstract}
Background: The evidence of decaffeinated coffee and green tea extract (DCGTE) in amelioration of atherosclerosis through foam cell formation inhibition has not been established. This study tried to predict the potential role of coffee and tea in foam cell inhibition through in silico modelling and to investigate the effect of DCGTE on the viability and regulation of foam cell inhibition effect in macrophage cell. Methods: Prediction of physicochemical properties of secondary metabolite of coffee and tea was computed with Swiss ADME. Simulation of molecular docking was performed using PyRxAutodock Vina. Prediction of biological activities was done with PASS SERVER and analyzed the suitability with KEGG Pathway: lipid and atherosclerosis. The effect of DGCTE on macrophage viability was assessed with WST-1 assay then synergistic score was calculated with Synergy Finder. The effect of DCGTE in foam cell formation was examined with light microscope after stained with ORO on oxLDL-stimulated Raw264.7. Results: Molecular docking analysis revealed a strong affinity binding between all active compound of tea or coffee with CD36, but not with PPARy. Except EGCG, the active compound of tea and coffee fulfil the criteria of drug-likeness. The online prediction function demonstrated that secondary metabolites of coffee and tea potentially inhibit foam cell atherosclerosis. No cytotoxicity effect was obtained after the 24 hours treatment of serial dose of DGCTE $10-640 \mu \mathrm{g} / \mathrm{ml}(\mathrm{p}=0.000)$. Moreover, the DGCTE $(320 / 320 \mu \mathrm{g} / \mathrm{ml}$ ) had a synergistic effect (Loewe score $=17.26417)$ and significantly reduced the foam cell number in oxLDL-stimulated Raw264.7 compared to control $(p=0.000)$. Conclusion: The DCGTE exhibit potential benefit as candidate agent for the prevention of atherosclerosis-based diseases.

Key words: Atherosclerosis, Coffee polyphenol, Foam cells, Molecular docking, Tea flavonoid.
\end{abstract}

\section{INTRODUCTION}

Atherosclerosis is the etiology of cardiovascular disease which is the leading cause of mortality worldwide ${ }^{1}$. To date, no specific therapies either pharmacologically or non-pharmacologically has been successfully prevent atherosclerosis. Statins and aspirin which are still become the available medication for atherosclerosis have several limitations. These medications only slightly lower the level of plaque. Moreover, the prolonged use of the drugs is widely reported for its adverse side effects like provoke toxicity to liver cells, induce rhabdomyolysis, increase the risk of cancer, and impair the cognitive function ${ }^{2-4}$. Moreover, upper Gastrointestinal (GI) bleeding is the most common complication in patients consuming aspirin ${ }^{5}$. However, only limited evidence showed that primary prevention either with statins or aspirin may be costeffective and improve patient quality of life ${ }^{2}$.

Based on these evidences, investigating the potency of natural product is urgently required for developing effective prevention strategy to limit the burden of the disease. Coffee is the most popular beverages in society nowadays which show safety in long term use. Yet, the presence of caffeine in coffee cause cardiovascular and non-cardiovascular side effect. Interestingly, a report from Lukitasari et al (2020) showed that a combination of decaffeinated coffee combined with tea has a beneficial effect on improving the lipid profile, blood pressure, blood glucose, and liver PPAR $y$ expression in the mice metabolic syndrome model ${ }^{6}$. Remarkable studies demonstrated that the polyphenol found in coffee and tea has benefits in reducing cardiovascular disease risk by their action as hypolipidemic, antioxidant, and anti-inflammatory properties ${ }^{7-11}$.

However, the evidence of decaffeinated coffee and green tea combination in preventing early phase of atherosclerosis remains unclear. Foam cell formation is the pathological process that not only determines the initial phase but also the progression of advanced phase atherosclerosis ${ }^{12-14}$. Two important molecules that dysregulate during foam cell formation are CD36 and PPAR $\gamma$. Perturbation of CD36 is seen by the upregulation of this protein to continuously accelerate the oxLDL uptake. In addition, the lipid derivative from oxLDL inside the macrophage will diminish PPAR $\gamma$ function to induce ATP Binding Cassettes Transporter A1 (ABCA1) expression, reducing the cholesterol efflux.

Therefore, the recent study aimed to predict affinity binding of coffee and tea secondary metabolite as competitive inhibitor of oxLDL to bind with CD36 and PPAR $\gamma$ which never done before. This study tried to predict the anti-atherosclerosis role of bioactive constituents in coffee: caffeine, chlorogenic acid (CGA), diterpenes (Cafestol, Kahweol) and trigonelline ${ }^{15}$, and in green tea: Epigallocatechin gallate (EGCG), Epigallocatechin (EGC), Epicatechin (EC), and Epicatechin Gallate(ECG) $)^{16}$ Secondly, in vitro study was performed to see the cytotoxicity of the decaffeinated coffee and green tea extract in Raw264.7 compared to individual extract. Another objective of this study was investigating

Cite this article: Rachmawati E, Rohman MS, Sishartami LW, Sargowo D, Kalsum U. In Silico Modelling, Regulation of Cell Viability and Anti Atherosclerotic Effect in Macrophage by Decaffeinated Coffee and Green Tea Extract. Pharmacogn J. 2022;14(1): 46-55. 
the effect of DCGTE in foam cell formation. We propose that this combination could provide a safe source for developing functional foods for atherosclerosis-based disease prevention.

\section{MATERIAL AND METHODS}

\section{Pharmacokinetic properties and prediction function of coffee and tea bioactive molecules}

Various pharmacokinetic properties and Lipinski rule of 5 which covers the drug-likeness properties of the active biomolecules were predicted using Swiss ADME online software ${ }^{17}$. Early Atherosclerosis is determined by foam cell formation. the PASS Server http://www. pharmaexpert.ru/passonline/index.php) investigated the biological activities related to each active compound ${ }^{18}$. The score listed in PASS SERVER followed the criteria: If $\mathrm{Pa}>0.7$, the substance was very likely to show activity in the experiment, but the probability of the substance being an analogue of a known pharmaceutical agent is also high. If 0.5 $<\mathrm{Pa}<0.7$, the substance was likely to show activity in the experiment, but the probability is less, and the substance was unlike any known pharmaceutical agent. If $\mathrm{Pa}<0.5$, the substance is unlikely to show activity in the experiment. Therefore, this study used cut off $\mathrm{Pa}>0.5^{19}$. The PASS SERVER data than matched with KEGG Pathway hsa 05417: lipid and atherosclerosis

\section{Ligand preparation}

The structure of 4 main active ingredients in coffee and tea were retrieved from the Pubchem crystal database server in SDF format (https:// pubchem.ncbi.nlm.nih.gov). Then all the .sdf files were converted to .pdb files using Pymol software. Four bioactive compounds of green coffee named CGA, cafestol, kahweol, trigonelline (Compound ID : $1794427,108052,114778,5570)$ were used in this study. EGCG, EGC, EC, ECG (Compound CID: 65064, 72277, 72276, 10795) as the main compound of green tea were also used in this study. The control for CD36 receptor was AP525820. The ligand control for PPAR $\gamma$ was Pioglitazone which was PPAR $\gamma$ agonist and used broadly as antidiabetic drug ${ }^{21}$.

\section{Receptor Preparation and Molecular docking}

oxLDL are key factor that promote the foam cell atherosclerosis through its binding with CD36 that is expressed in activated macrophage ${ }^{14,22,23}$. Additionally, ox-LDL binding with PPAR $\gamma$ in macrophage could exert the increase expression of CD36 thus accumulate the lipid inside the macrophage and propagate the foam cell number ${ }^{24}$. Hence, an investigation to find alternative ligand for CD36 and PPAR $\gamma$ should be performed.

The X-ray crystal structures of Human Platelet Glycoprotein 4 (CD36) (PDB 5LGD Chain A) and PPAR- $\gamma$ (PDB 5Y2O) were retrieved from the PDB database (http://www.rcsb.org). All proteins were modelled with the PyMol program by removing all the water molecules and sulphate ions present in the structure. Then the structure was optimized by assigning the bond orders, bond angles, and topology. The formal atomic charges were fixed for the amino acid residues. The optimized structure was then energy minimized to remove the steric clashes between the atoms ${ }^{25}$.

The binding affinities of the ligand and receptors were determined by docking CD36 and PPAR $\gamma$ with the bioactive molecule of coffee and tea using PyRx AutoDock Vina ${ }^{26}$. The active binding site information was obtained through the webserver active site prediction http://www. scfbio-iitd.res.in/dock/ActiveSite.jsp. This results in a higher level of confidence in predicting one or more protein binding regions, as well as a more accurate ranking of the likely binding sites. The position of the active site region was used to determine the center of the grid box for CD36 and PPAR $\gamma$. The center of the grid box for CD36 and
PPAR $\gamma$ was chosen based on the location of the active site region.. The specific docking for CD36 and PPAR- $\gamma$ with grid box were at Center (X: -44.484594093, Y: -34.1146354603, Z: 22.1589056284), Domain (x $=17.5598077147, \mathrm{y}: 15.6844124884, \mathrm{z}=16.4742530197)$ and Center (X : - 48.584; Y : -1.611; Z: 77.668), Dimension (X: 10.278; Y:13.425; $\mathrm{Z}: 17.929)$, respectively. These suitable grid boxes volume was the site where the ligands can easily be fitted and which covers the entire active site pocket. Amongst them, the best-suited conformations with the lowest root mean square deviation (RMSD) values were selected to calculate the binding energetics. The obtained docked products were visualized and analyzed the hydrogen bond interactions and preparation of high-resolution images by Biovia Discovery Studio software $^{27}$.

\section{Extraction of coffee and tea}

Robusta green coffee beans from the Dampit district of Malang Regency, Indonesia, were used in this study as the raw material. The sample utilized was powdered green coffee beans that had been roasted for 3 minutes at $180^{\circ} \mathrm{C}$. For the tea extract processing, 3 green tea leaves were taken from the tallest section of trees in the Ciwidey district of Bandung. ${ }^{28}$

The coffee and green tea were extracted using infusion technique ${ }^{29}$. The Fischer and Liang et al. in 2007 method was used to decaffeinate the coffee and green tea, respectively. The light-roasted ground coffee beans were boiled for 10 minutes at $90^{\circ} \mathrm{C}$ in mineral water, then filtered through fine filter paper. The filtrate was decaffeinated for 8 hours at $60^{\circ}$ C 27 using activated charcoal ${ }^{30}$. After the dried tea leaves were boiled for 5 minutes at $50^{\circ} \mathrm{C}$ in mineral water then filtered using Whatman paper No 1, the filtrate was infused in $90^{\circ} \mathrm{C}$ water for 30 minutes ${ }^{31}$.

\section{Cell culture}

RAW 264.7 macrophages, a mouse macrophage cell line obtained from ATCC passage 13-15, were cultured in Dulbecco's modified Eagle's medium (DMEM high glucose), supplemented with 10\% Fetal Bovine Serum (FBS, Gibco) and 1\% Penicilin/Streptomycin (P/S, Gibco) in a $5 \% \mathrm{CO} 2$ incubator at $37^{\circ} \mathrm{C}$ in $60 \mathrm{~mm}$ dish culture.

\section{Viability test and synergistic prediction}

Briefly, RAW 264.7 was seeded at 50.000 cells /well in 96 well plates and incubated at $37^{\circ} \mathrm{C}$ in a $5 \% \mathrm{CO} 2$ incubator for 24 hours. The next day, the medium was replaced with tea and coffee extract at $0,10,20,40,80$, $160,320,640,1280$, and $2560 \mu \mathrm{g} / \mathrm{ml}$ and incubated for 24 hours. The WST-1 based cell proliferation and cytotoxicity assay kit obtained from Roche Diagnostics GmbH (Mannheim, Germany) Cat. No. 05015944001 was added to each well at the end of the treatment, and the plates were incubated for $1 \mathrm{~h}$ in the dark. Finally, absorbance was measured at $450 \mathrm{~nm}$ with a microtiter plate reader (Asys, Cambridge, England).

The synergy finder was used to see the synergistic potency of the coffee and tea combination. The summary synergy scores can be interpreted as follow: (1) Less than -10: the interaction between two drugs is likely to be antagonistic; (2) From -10 to 10: the interaction between two drugs is likely to be additive; (3) Larger than 10: the interaction between two drugs is likely to be synergistic ${ }^{32}$.

\section{Construction of Foam cell model and staining}

The RAW 264.7 cells were plated in 24-well plates placed with coverslip with an initial cell density of 15.000 cells/well and cultured for 24 hours. After this period, cells were treated with M-CSF $50 \mathrm{ng} / \mathrm{ml}$. The next day after treated with coffee and tea combination extract, a foam cell model was established by incubation of cells with oxLDL $50 \mu \mathrm{g} / \mathrm{ml}$ for $24 \mathrm{~h}$.

Before staining, the working solution of ORO was made from Oil Red $\mathrm{O}$ stock solution. The Stock solution was made by dissolving $0.5 \mathrm{~g}$ Oil 
Red O powder (Sigma) in $80 \mathrm{ml}$ isopropanol (100\%) in water bath with a temperature of $56{ }^{\circ} \mathrm{C}$ overnight. The container was sealed to prevent the evaporation of isopropanol. The final volume of the stock was adjusted to $100 \mathrm{ml}$ and mixed under gentle stirring (IKA Working Group, Germany). Before staining, the stock solution was pre-warmed to $60^{\circ} \mathrm{C}$ and filtered with number 1 filter paper (Whatman, UK). A working solution was prepared by diluting the stock solution 3:2 with deionized water, allowing to stand for $10 \mathrm{~min}$ at room temperature and then filtered $(0.22 \mu \mathrm{m} \text {, Millipore })^{33}$.

The medium was aspirated and cells were rinsed twice with $0.01 \mathrm{M}$ PBS. The cells were fixed in $10 \%$ paraformaldehyde for $10 \mathrm{~min}$. Rinsing The cells were rinsed in PBS once $(1 \mathrm{~min})$ then rinsed in $60 \%$ isopropanol for 30 minutes to facilitate the staining of neutral lipids. The cells were stained with filtered Oil Red $\mathrm{O}$ working solution at $37^{\circ} \mathrm{C}$ for $30 \mathrm{~min}$ in darkness. Aspirated the ORO staining, then washed with PBS for 3 times, 3 min each. Mounting on microscope Positive-staining (red) cells were macrophage-derived foam cells, which were observed via light microscope (Olympus) and then photographed using Image ProPlus 6.0 software(Media Cybernetics) ${ }^{33}$.

\section{Statistical analysis}

In silico data were presented using descriptive statistic. Statistical analyses of RAW 264.7 viability and foam cell number after administration of DCGTE were determined with SPSS 24.0 software by Anova one way test. Differences with $P$ values $\leq 0.05$ were considered statistically significant.

\section{RESULTS}

The physicochemical characteristic, prediction of pharmacokinetics, and mechanism of coffee and tea secondary metabolites

Designing new drugs must consider the assessment of absorption, distribution, metabolism, and excretion (ADME) which could be performed using computer models that constitute a valid alternative to experiments. Six physicochemical as properties are taken into account that gives a global description of the structure that could predispose the Bioavailability of the molecule and also highlight the propensity of the molecule to interfere with biological assays when research is conducted. The results on predictive data for pharmacokinetics, bioavailability, drug-likeness of established 8 Phyto-ligands were depicted in Table 1 . The analysis of drug-likeness using the Lipinski Rule concluded that EGCG did not fulfil the criteria of a drug and also have low bioavailability score.

Early atherosclerosis is marked by upregulation of inflammatory transcription factor and its product, dysregulation of cholesterol metabolism inside macrophage due to high LDL penetration, and modification in subendothelial space. Therefore, the prediction of the potential biological process of coffee and tea to regulate the important process of atherosclerosis contributes to important data for further research as depicted also in Table 2. It was concluded that all active constituent of tea had a strong potency to inhibit atherogenesis through several pathways, but not with coffee. The cafestol and kahweol did not exert anti atherogenic properties based on PASS SERVER analysis.

\section{Molecular Docking Simulation}

Molecular docking analysis of 4 coffee (CGA, Cafestol, Kahweol, Trigonellin) and tea compounds (EGCG, EGC, ECG, EC) with target proteins (CD36, PPAR $\gamma$ ) were presented in Table 3.

The results obtained were validated based on the binding affinities score and hydrogen bond interaction. EGCG, the largest content of tea active compound, became the strong candidate to bind with CD36 (Binding affinity $=-9.0>-8.5$ ). Interestingly, the bioactive molecule interaction with PPAR $\gamma$ showed reverse predictive potency compared with the binding with CD36. The highest potency of binding with PPAR $\gamma$ was CGA, the most active constituent of coffee. The kahweol, cafestol, EC, and ECG, which have binding affinity value close to control, had a potency to further investigation as an anti-atherosclerotic agent. The binding affinity of trigonelline to CD36 and PPAR $\gamma$ was the lowest among others, thus we assumed that the potency as an oxLDL inhibitor for the receptors was low. The detail interaction of binding was presented in Figure 2.

\section{The effect of decaffeinated coffee or green tea extract on RAW264.7 viability}

The WST-1 method was used to determine cell viability after being treated with coffee or green tea extracts for $24 \mathrm{~h}$. This test was used to determine the ratio of decaffeinated coffee extract (DCE) and decaffeinated green tea extract (DGTE) that would be used for combination and to identify the dose that tended to reduce the viability of the cells below $100 \%$. The comparation of mean and standard deviation of Raw viability value from Table 4 between DCE and DGTE group was similar in each dose, thus for the combination we used ratio 1:1.

Figure 3 demonstrated the significant difference of percentage viability in cells treated with DCE and DGTE $(0-1280 \mu \mathrm{g} / \mathrm{ml})$ compared with control $(\mathrm{p}<0.05)$. The cell administrated with the extract showed higher viability than control.

\section{The synergistic effect of decaffeinated coffee and green tea extract on RAW264.7 viability}

The serial dose $0-640 / 640 \mu \mathrm{g} / \mathrm{ml}$ of DCGTE was exposed to Raw264.7 for 24 hours and compared with the administration of DCE or DGTE $(0-640 \mu \mathrm{g} / \mathrm{ml})$. The data showed the viability of DCGTE was higher than DCE or DGTE as shown in Table 5.

To validated the suggestion of synergistic effect found in coffee and tea combination, we performed a serial viability test with a variety of doses and analysed the result in synergy finder. The total score of coffee and tea combination using the Loewe method was 11.96, thus it was concluded that the combination was synergistic. The percentage viability of Raw264.7 after administered with coffee-tea combination and Loewe score were depicted in Figure 4.

\section{Effect of decaffeinated coffee and green tea extract on foam cell formation}

The effect of the DCGTE on foam cell formation was assessed and presented in Figure 5. The data demonstrated a significant difference between the foam cell number between group treated with DCGTE compared to control $+(p=0,000)$. Hence, the DCGTE $320 / 320 \mu \mathrm{g} / \mathrm{ml}$ reduced foam cell number in oxLDL-exposed Raw264.7.

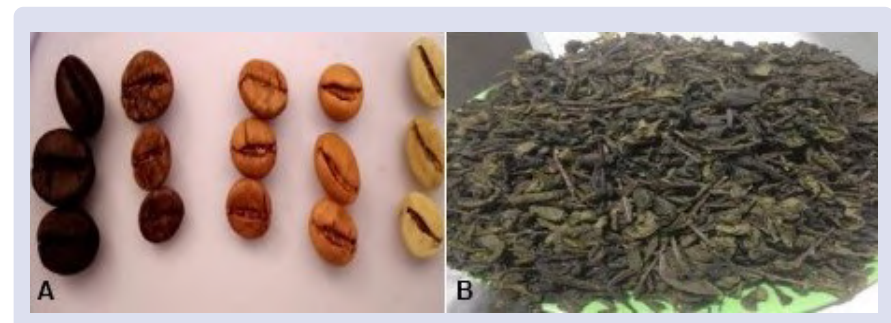

Figure 1: Coffee and tea preparation before extraction and decaffeination process.

(A)The selected raw green coffee bean was roasted for 3 minutes in $180^{\circ} \mathrm{C}$ until the first crack which was seen as a line inside the bean (the $3^{\text {rd }}$ column). (B)The selected green tea leaves were dried under the sun which formed rolls. 


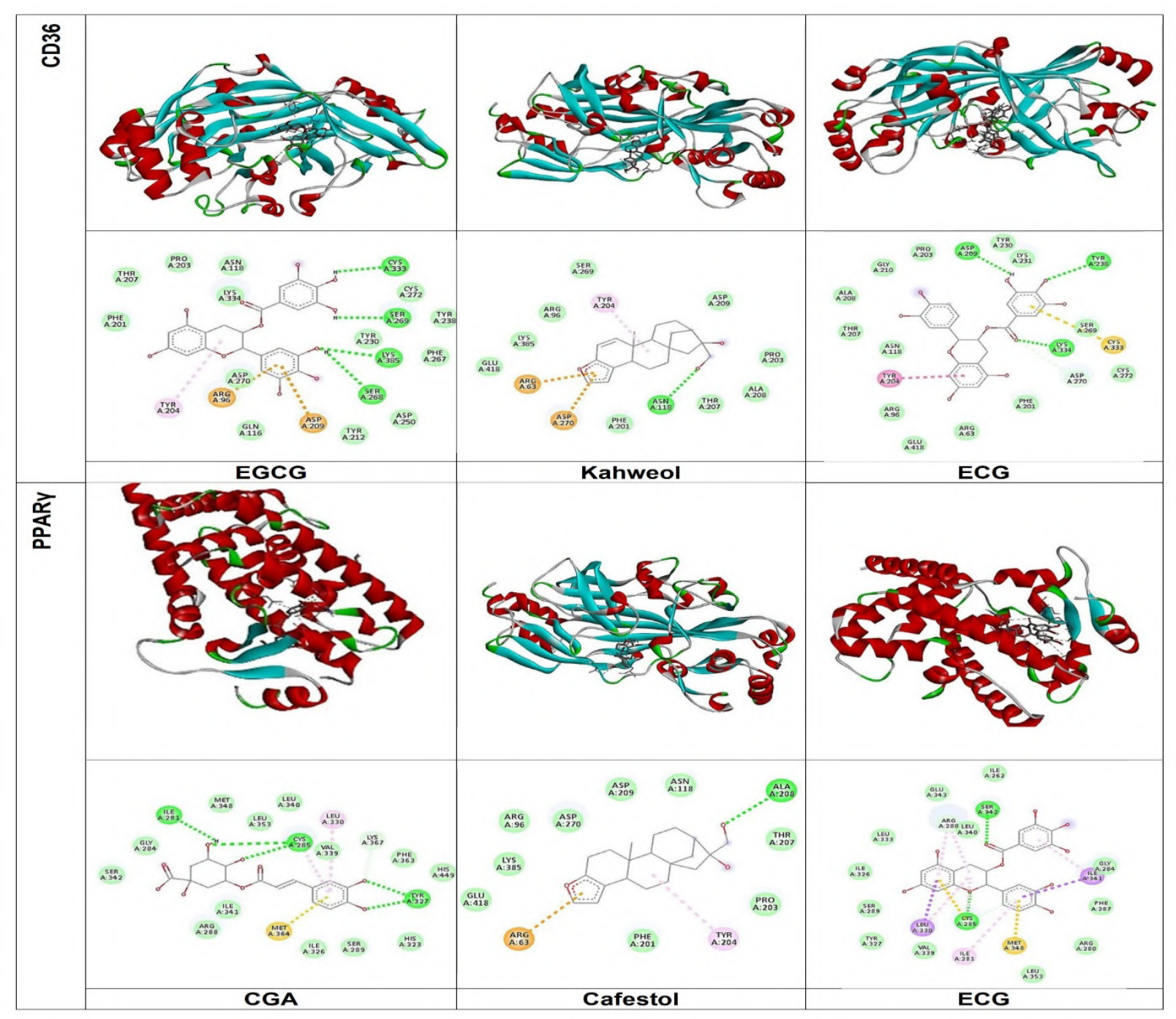

Figure 2: $3 \mathrm{D}$ and $2 \mathrm{D}$ binding interaction view of top 3 coffee and tea active ingredients with CD36 and PPARY.

3D visualization: red cylindrical spiral; Blue and grey strand indicated secondary structure of protein $a$-helices and $\beta$-sheet, respectively. 2D visualization : Green, light green, purple, orange circles represented conventional hydrogen bonds, carbon hydrogen bonds, alkyls, anions, respectively.

Table 1: Pharmacokinetics and biological process analysis related to coffee and tea main active ingredients.

\begin{tabular}{|c|c|c|c|c|c|c|c|c|}
\hline \multicolumn{9}{|c|}{ Physics and chemical properties } \\
\hline \multirow{4}{*}{$\begin{array}{l}\text { Consensus } \log P_{\mathrm{o} / \mathrm{w}} \\
\log S(\mathrm{ESOL}) \mathrm{mg} / \mathrm{ml} \\
\text { solubility }(\mathrm{mol} / \mathrm{l}) ; \\
\text { class }\end{array}$} & \multicolumn{4}{|c|}{ Tea active constituents } & \multicolumn{4}{|c|}{ Coffee active constituents } \\
\hline & EGCG & EGC & ECG & EC & CGA & Cafestol & Kahweol & Trigonelline \\
\hline & 1.01 & 0.42 & 1.23 & 0.85 & -0.38 & 3.24 & 3.18 & -0.61 \\
\hline & $\begin{array}{l}-3.56 ; .27 \mathrm{e}-01 ; \\
2.76 \mathrm{e}-04 ; \text { soluble }\end{array}$ & $\begin{array}{l}-2.08 ; 2.57 \mathrm{e}+00 \\
8.39 \mathrm{e}-03 ; \text { soluble }\end{array}$ & $\begin{array}{l}-3.70 ; 8.85 e-02 ; \\
2.00 e-04 ; \text { soluble }\end{array}$ & $\begin{array}{l}-2.22 ; 1.74 \mathrm{e}+00 \\
5.98 \mathrm{e}-03 ; \text { soluble }\end{array}$ & $\begin{array}{l}-1.62 ; 8.50 \mathrm{e}+00 \\
2.40 \mathrm{e}-02 ; \text { soluble }\end{array}$ & $\begin{array}{l}-3.96 ; 3.44 \mathrm{e}-02 \\
1.09 \mathrm{e}-04 ; \text { soluble }\end{array}$ & $\begin{array}{l}-4.03 ; 2.96 \mathrm{e}-02 \\
9.41 \mathrm{e}-05 ; \text { soluble }\end{array}$ & $\begin{array}{l}-1.39 ; 5.59 \mathrm{e}+00 ; \\
4.08 \mathrm{e}-02 ; \text { very } \\
\text { soluble }\end{array}$ \\
\hline GI absorption & Low & High & Low & High & Low & High & High & High \\
\hline BBB permeant & No & No & No & No & No & Yes & Yes & No \\
\hline P-gp substrate & No & No & No & Yes & No & Yes & Yes & No \\
\hline CYP1A2 inhibitor & No & No & No & No & No & No & No & No \\
\hline CYP2C19 inhibitor & No & No & No & No & No & No & No & No \\
\hline CYP2C9 inhibitor & No & No & No & No & No & Yes & Yes & No \\
\hline CYP2D6 inhibitor & No & No & No & No & No & No & No & No \\
\hline CYP3A4 inhibitor & No & No & No & No & No & No & No & No \\
\hline Lipinski & $\begin{array}{l}\text { No; } 2 \text { violations: } \\
\mathrm{N} \text { or } \mathrm{O}>10, \mathrm{NH} \\
\text { or } \mathrm{OH}>5\end{array}$ & $\begin{array}{l}\text { Yes; } 1 \text { violation: } \\
\mathrm{NH} \text { or } \mathrm{OH}>5\end{array}$ & $\begin{array}{l}\text { Yes; } 1 \text { violation: } \\
\mathrm{NH} \text { or } \mathrm{OH}>5\end{array}$ & Yes; 0 violation & $\begin{array}{l}\text { Yes; } 1 \text { violation: } \\
\mathrm{NH} \text { or } \mathrm{OH}>5\end{array}$ & Yes; 0 violation & Yes; 0 violation & Yes; 0 violation \\
\hline Bioavailability Score & 0.17 & 0.55 & 0.55 & 0.55 & 0.11 & 0.55 & 0.55 & 0.55 \\
\hline
\end{tabular}



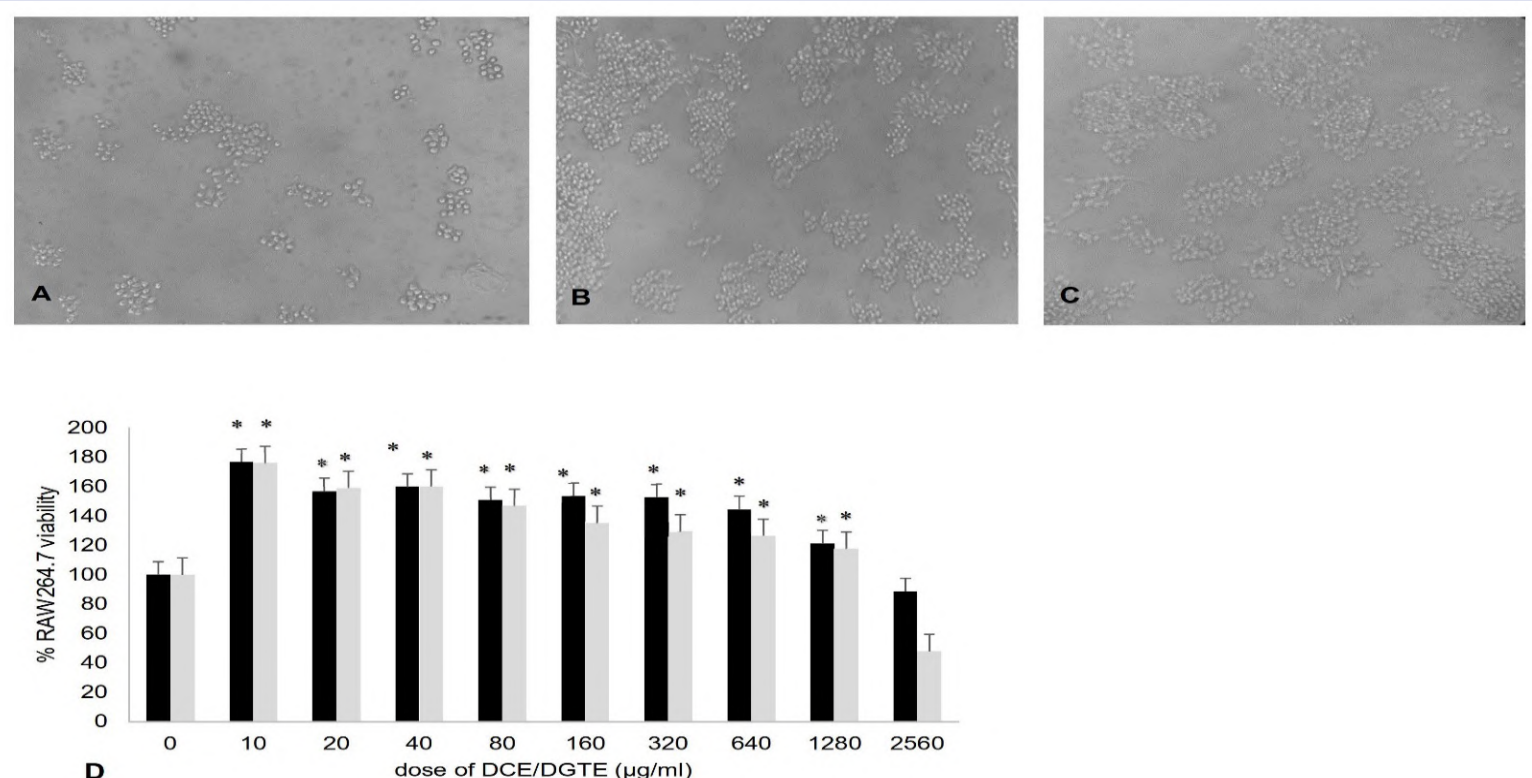

Figure 3: The effect of DCE and DGTE on viability of Raw 264.7 cells. Cells in 96 well plate $\left(5 \times 10^{4}\right.$ cells/well) were incubated with : (A) Complete medium; (B) DCE and (C) DGTE dose $320 / 320 \mu \mathrm{g} / \mathrm{ml}$ for 24 hours. (D)The histogram depicted viability percentages of cell after treated with the extract. Each value is expressed as mean \pm SD in three different experiments performed in triplicate.* indicated $p<0.05$ relative to control ( dose $0 \mu \mathrm{g} / \mathrm{ml}$ ).

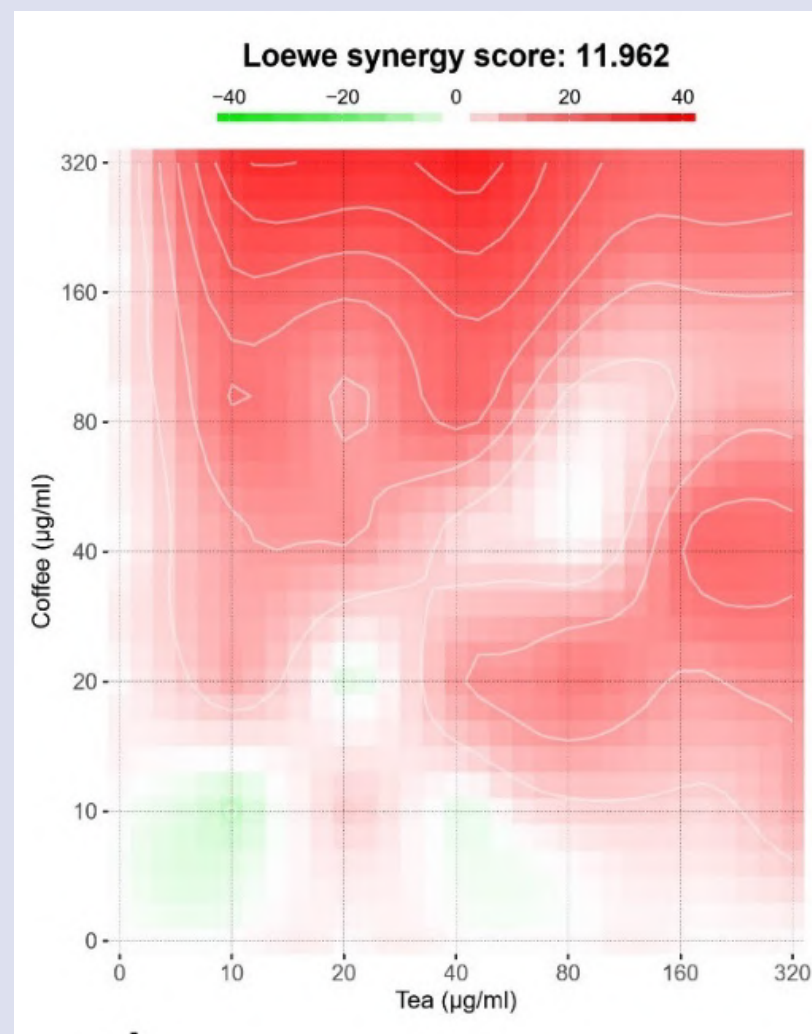

A

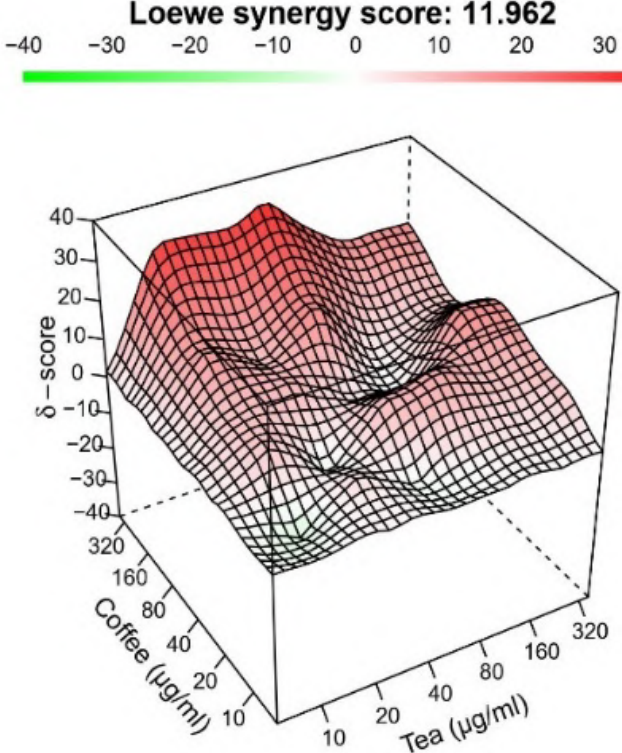

B

Figure 4: The synergistic Loewe score of DCGTE. (A) The 2D plot of synergy distribution; and (B) The 3D synergy landscape plot. The overal Loewe score was 11.962 , therofore the combination showed synergistic effect. The optimal dose based on Synergy Finder was at 320/320 $\mu \mathrm{g} / \mathrm{ml}$ (score=17.26417). 

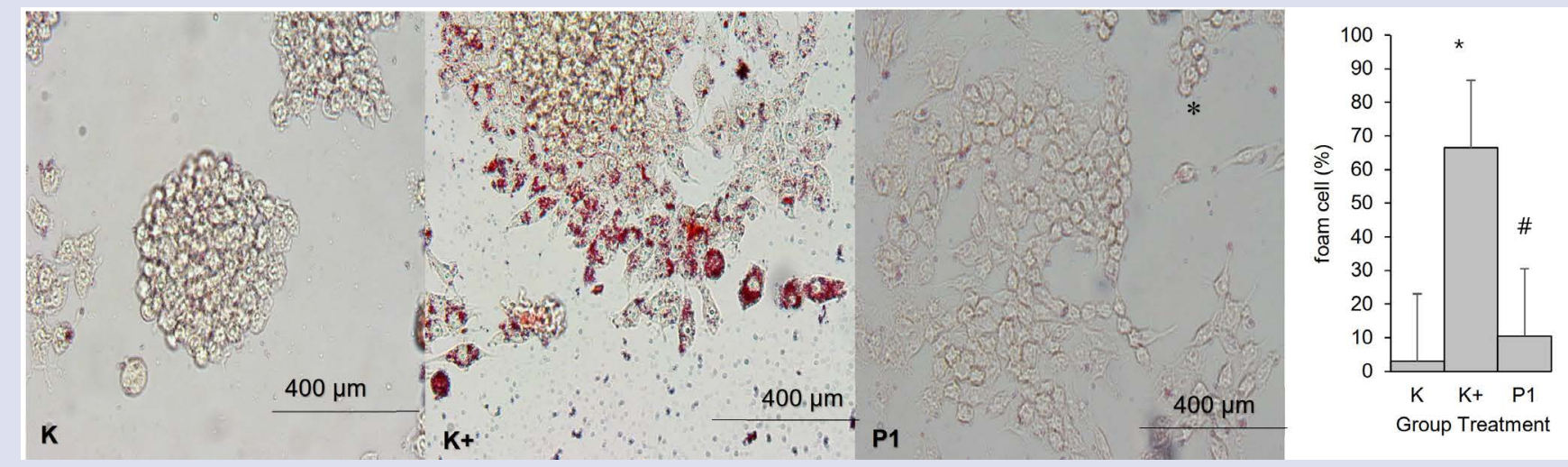

Figure 5: Foam cell percentage in oxLDL- stimulated Raw264.7 . (a) The foam cell formation was evaluated under light microscope 200x magnification (K) Control groups: Raw $264.7+\mathrm{M}-\mathrm{CSF} 50 \mathrm{ng} / \mathrm{ml}$; (K+) : Raw $264.7+\mathrm{M}-\mathrm{CSF} 50 \mathrm{ng} / \mathrm{ml}+$ oxLDL $50 \mu \mathrm{g} / \mathrm{ml}$, and (P1) : Raw 264.7+M-CSF $50 \mathrm{ng} / \mathrm{ml}+$ DCGTE $320 / 320 \mu \mathrm{g} / \mathrm{ml}+\mathrm{oxLDL} 50 \mu \mathrm{g} / \mathrm{ml}$. The foam cell is the cell coloured red in the cytoplasm after ORO staining. The data were taken after triplicate experiment. Histogram showed the $\%$ of foam cell in tririplicate. ${ }^{*} p<0,05$ relative to control (K), and \# $p<0.05$ relative to $\mathrm{K}+$.

Table 2: Predicted biological activities of coffee and tea active compound.

\begin{tabular}{|c|c|c|c|c|c|c|c|c|}
\hline \multicolumn{9}{|l|}{ Biological process } \\
\hline & \multicolumn{4}{|c|}{ Tea active constituents } & \multicolumn{4}{|c|}{ Coffee active constituents } \\
\hline & EGCG & EGC & ECG & EC & CGA & Cafestol & Kahweol & Trigonelline \\
\hline Lipid peroxidase inhibitor & 0.946 & 0.92 & 0.948 & 0.85 & & & & \\
\hline Hypolipidemic agent & 0.70 & 0.71 & 0.54 & 0.63 & & & & \\
\hline Anti-inflammatory & 0.62 & 0.61 & 0.61 & 0.54 & 0.59 & & & \\
\hline Transcription factor NF kappa B inhibitor & & & 0.57 & 0.7 & & & & \\
\hline TNF inhibitor & 0.57 & 0.71 & 0.57 & 0.51 & 0.52 & & & \\
\hline Ubiquinol-cytochrome-c reductase inhibitor & 0.59 & & 0.57 & 0.73 & 0.58 & & & 0.67 \\
\hline Antioxidant & 0.82 & 0.87 & 0.786 & 0.81 & 0.785 & & & \\
\hline ApoA1 enhancer & 0.85 & 0.85 & 0.849 & 0.863 & 0.62 & & & 0.60 \\
\hline
\end{tabular}

Table 3: Affinity binding of coffee and tea active compounds for CD36 and PPARy ligand.

\begin{tabular}{|c|c|c|c|}
\hline Chemical compound & Binding affinities (kcal/mol) & Number of $\mathrm{H}$-bond & Interacting residues \\
\hline \multicolumn{4}{|l|}{ CD36 } \\
\hline AP 5258 & -8.5 & 3 & ASN118, PRO203, SER269 \\
\hline EGCG & -9.0 & 4 & CYS333, LYS334, PRO203, ASP270 \\
\hline EGC & -7.8 & 1 & ARG96 \\
\hline ECG & -8.4 & 3 & LYS334, ASP209, TYR238 \\
\hline $\mathrm{EC}$ & -8.2 & 1 & ARG96 \\
\hline CGA & -8.2 & 3 & LYS385, ARG96, PRO203 \\
\hline Cafestol & -8.2 & 1 & ALA208 \\
\hline Kahweol & -8.4 & 1 & ASN118 \\
\hline Trigonelline & -5.3 & 4 & SER268, SER 269, ASP270, LYS385 \\
\hline \multicolumn{4}{|l|}{$\operatorname{PPAR} \gamma$} \\
\hline Pioglitazone & -8.8 & 3 & HIS323, SER289, TYR473 \\
\hline EGCG & -5.4 & 3 & TYR473, SER289, ILE326 \\
\hline EGC & -6.9 & 3 & CYS285, HIS449, SER289 \\
\hline ECG & -6.5 & 2 & SER342, CYS285 \\
\hline $\mathrm{EC}$ & -6.8 & 1 & SER342 \\
\hline CGA & -7.3 & 3 & ILE281, CYS285, TYR327 \\
\hline Cafestol & -6.9 & 1 & ARG280 \\
\hline Kahweol & -5.8 & 1 & SER342 \\
\hline Trigonelline & -5.2 & 3 & TYR327, HIS449, SER289 \\
\hline
\end{tabular}


Table 4: Viability of Raw 264.7 after treated with DCE and DGTE.

\begin{tabular}{|c|c|c|c|c|}
\hline $\begin{array}{c}\text { Dose } \\
(\mu \mathrm{g} / \mathrm{ml})\end{array}$ & $\%$ Viability groups DCE & $\mathbf{p}$ & $\%$ Viability groups DGTE & $p$ \\
\hline 10 & $176.72 \pm 3.58$ & \multirow{9}{*}{$0.000^{* *}$} & $176.97 \pm 5.13$ & \multirow{9}{*}{$0.000^{\star *}$} \\
\hline 20 & $163.54 \pm 19.11$ & & $154.22 \pm 4.04$ & \\
\hline 40 & $159.66 \pm 21.11$ & & $152.03 \pm 7.51$ & \\
\hline 80 & $156.39 \pm 1.769$ & & $147.29 \pm 11.76$ & \\
\hline 160 & $154.42 \pm 33.53$ & & $137.07 \pm 2.39$ & \\
\hline 320 & $152.42 \pm 10.66$ & & $124.07 \pm 9.87$ & \\
\hline 640 & $147.65 \pm 37.36$ & & $116.17 \pm 11.53$ & \\
\hline 1280 & $110.21 \pm 6.86$ & & $110.42 \pm 10.66$ & \\
\hline 2560 & $89.74 \pm 5.68$ & & $61.13 \pm 7.65$ & \\
\hline
\end{tabular}

The data were presented as mean and standard deviation in each group.* $\mathrm{p}<0.05$ relative to control; ${ }^{* *} \mathrm{p}<0.001$ relative to control

Table 5: The effect of DCE, DGTE, and DCGTE on macrophage Raw264.7 viability.

\begin{tabular}{|c|c|c|c|c|c|c|c|}
\hline Dose $(\mu \mathrm{g} / \mathrm{ml})$ & $\begin{array}{c}\% \text { Viability of } \\
\text { DCE }\end{array}$ & $p$ & $\begin{array}{c}\% \text { Viability of } \\
\text { DGTE }\end{array}$ & $p$ & Dose $(\mu \mathrm{g} / \mathrm{ml})$ & $\begin{array}{c}\% \text { Viability of } \\
\text { DCGTE }\end{array}$ & $p$ \\
\hline 10 & $161.79 \pm 4.54$ & & $164.25 \pm 14.61$ & & $10 / 10$ & $190.03 \pm 14.93$ & \\
\hline 40 & $138.38 \pm 5.80$ & & $139.25 \pm 6.58$ & & $40 / 40$ & $159.77 \pm 16.72$ & \\
\hline 80 & $135.16 \pm 6.92$ & $0.000^{* *}$ & $137.89 \pm 5.66$ & $0.000^{* *}$ & $80 / 80$ & $154.75 \pm 4.84$ & $0.009^{\star *}$ \\
\hline 640 & $121.28 \pm 5.72$ & & $111.12 \pm 1.32$ & & $640 / 640$ & $133.92 \pm 34.00$ & \\
\hline
\end{tabular}

The data were expressed as mean and standard deviation in each group. ${ }^{*} \mathrm{p}<0.05$ relative to control; ${ }^{* *} \mathrm{p}<0.001$ relative to control

\section{DISCUSSION}

Exploring natural product as candidate agent for prevention of atherosclerosis is crucial effort for reducing the cardiovascular disease prevalence. Many studies reported the effect of coffee consumption in reducing cardiovascular risk, thus become one functional food candidate in the prevention of the disease. Yet, several reports did not successfully reveal the beneficial effect of coffee in lowering cardiovascular disease. Therefore, our current study tried to alleviate the coffee health effect by several strategies: (1) performing light roasting to coffee bean, (2) decaffeination, and (3) combining coffee with tea based on preliminary study. The total CGA content of green coffee beans $(34.43-41.64 \mathrm{mg}$ $/ \mathrm{g})$ is much higher than that of light and medium roasted coffee $(2.05$ - $7.07 \mathrm{mg} / \mathrm{g}$ ) because CGA undergoes isomerization and decomposes with heat. Decaffeination process minimize the caffeine concentration which cause cardiovascular or non-cardiovascular side effects by consuming coffee ${ }^{34,35}$.

Our findings showed that either DCE, DGTE, or DCGTE did not induced cytotoxicity on macrophage cell. These results were supported by other in vitro studies. Five studies were examining the viability test after the cell exposed to coffee extract and three studies with green tea leaves extract. The average dose of green coffee extract that still viable to macrophage cell $90 \%$ was $500 \mu \mathrm{g} / \mathrm{ml}$, while for green tea was $125 \mu \mathrm{g} / \mathrm{ml}^{36,37}$.

The synergistic combination of active ingredients in coffee and tea has been reported by Mao et al 2017. The study showed that combination of CGA and EGCG has higher antioxidant activity compared to individual content ${ }^{38}$. The present study tried to get an overview of the potential role of DCGTE in inhibiting foam cell atherosclerosis. Our data demonstrated that DCGTE could suppress the foam cell formation. The mechanistic action of these extract might be explained by the in silico result. Based on molecular docking result, the tea preferably inhibits oxLDL uptake by competitive binding to CD36, meanwhile the coffee strongly suggested act as ligand for PPAR $\gamma$. A cluster of differentiation 36 (CD36) is a transmembrane glycoprotein family, a member of class B scavenger receptor. This receptor plays an important role in atherosclerosis development due to high expression in macrophage and facilitating the uptake of ox-LDL into macrophages ${ }^{23}$. Fatty Acid, another lipid derivate such as HODE in an oxLDL bind with high affinity to CD36. Many studies demonstrated that amino acids 160-168 of CD36 represent the core of the binding site for oxLDL and that the electrostatic interaction between evolutionary ${ }^{39}$. The PPAR $\gamma$ will activate the ABCA1 and mediated the efflux of cholesterol from the macrophage. Thus, our in silico findings gave information for developing coffee and tea as an antiatherosclerosis agent based on the molecular docking result and molecular function prediction. The prediction biological process supports the in vitro results. All coffee and tea active ingredients have potency either as: lipid peroxidase inhibitor, hypolipemic, anti-hypocholesterolaemia, anti-inflammatory, TNFa inhibitor, ubiquitin inhibitor, and ApoAl enhancer agent that has been matched with KEGG Pathway: lipid and atherosclerosis. Our study has several limitations since we did not investigate the molecular mechanism how the could lower foam cell.

\section{CONCLUSION}

Based on in silico and in vitro data, it was concluded that coffee and tea might have potential role in foam cell atherosclerosis. The DCGTE showed no cytotoxicity to the Raw264.7 cells and could inhibit foam cell formation. Further in vitro and in vivo research using atherosclerosis mice model need to be performed to see the cellular and molecular mechanism of combination of decaffeinated coffee and green tea on the atherosclerosis initiation and progression. The toxicity and safety aspects of products are also required to explore before commercialization. Apart from all, our findings give evidence that decaffeinated coffee and green tea could be a potential functional food candidate to replace the use of statin or aspirin as a previous drug to inhibit atherosclerosis.

\section{ETHICS STATEMENTS}

This is a computational and in vitro study, which doesn't include animal or human experiments. 


\section{DECLARATION OF COMPETING INTEREST}

The authors declare no conflicts of interest.

\section{REFERENCES}

1. Benjamin EJ, Muntner P, Alonso A, et al. Heart Disease and Stroke Statistics-2019 Update: A Report From the American Heart Association. Vol 139.; 2019. doi:10.1161/CIR.0000000000000659 available from: https://www.ahajournals.org/doi/10.1161/ CIR.0000000000000659

2. Lippi G, Plebani M. Statins for Primary Prevention of Cardiovascular Disease. Trends in Pharmacological Sciences. 2017;38(2):111-112. doi:10.1016/j.tips.2016.11.011 available from: https://pubmed.ncbi. nlm.nih.gov/28017363/

3. Li M, Wang $X$, Li X, et al. Statins for the Primary Prevention of Coronary Heart Disease. BioMed Research International. 2019;2019. doi:10.1155/2019/4870350 available from: https:// pubmed.ncbi.nlm.nih.gov/30834266/

4. Byrne P, Cullinan J, Smith A, Smith SM. Statins for the primary prevention of cardiovascular disease: An overview of systematic reviews. BMJ Open. 2019;9(4). doi:10.1136/bmjopen-2018-023085 available from: https://pubmed.ncbi.nlm.nih.gov/31015265/

5. Gelbenegger G, Postula M, Pecen L, et al. Aspirin for primary prevention of cardiovascular disease: A meta-analysis with a particular focus on subgroups. BMC Medicine. 2019;17(1):1-16. doi:10.1186/s12916-019-1428-0 available from: https://pubmed. ncbi.nlm.nih.gov/31679516/

6. Lukitasari M, Nugroho D, Rohman M, Widodo N, Farmawati A, Hastuti P. Beneficial effects of green coffee and green tea extract combination on metabolic syndrome improvement by affecting AMPK and PPAR-a gene expression. Journal of Advanced Pharmaceutical Technology and Research. 2020;11(2):81-85. doi:10.4103/japtr.JAPTR_116_19 available from: https://pubmed. ncbi.nlm.nih.gov/32587821/

7. Hao G, Li W, Teo K, et al. Influence of tea consumption on acute myocardial infarction in China population: The INTERHEART China study. Angiology. 2015;66(3):265-270. doi:10.1177/0003319714531849 available from: https://pubmed. ncbi.nlm.nih.gov/24755694/

8. Nikpayam O, Roshan H, Sohrab G, Sedaghat M. Effects of green coffee extract supplementation on oxidative stress, systemic and vascular inflammation in patients with metabolic syndrome: A randomized clinical trial. Iranian Red Crescent Medical Journal. 2018;20(6). doi:10.5812/ircmj.67971 available from: https:// pubmed.ncbi.nlm.nih.gov/29307310/

9. Mineharu $Y$, Koizumi A, Wada $Y$, et al. Coffee, green tea, black tea and oolong tea consumption and risk of mortality from cardiovascular disease in Japanese men and women. Journal of Epidemiology and Community Health. 2011;65(3):230-240. doi:10.1136/jech.2009.097311 available from: https://pubmed.ncbi. nlm.nih.gov/19996359/

10. Salamat S, Sharif SS, Nazary-Vanani A, Kord-Varkaneh H, Clark CCT, Mohammadshahi M. The effect of green coffee extract supplementation on serum oxidized LDL cholesterol and total antioxidant capacity in patients with dyslipidemia: A randomized, double-blind, placebo-controlled trial. European Journal of Integrative Medicine. 2019;28(May):109-113. doi:10.1016/j.eujim.2019.05.001 available from: https://pureportal.coventry.ac.uk/en/publications/ the-effect-of-green-coffee-extract-supplementation-on-serum-oxidi

11. Bønn SK, Ward NC, Hodgson JM, Croft KD. Effects of tea and coffee on cardiovascular disease risk. Food and Function. 2012;3(6):575591. doi:10.1039/c2fo10288a available from: https://pubmed.ncbi. nlm.nih.gov/22456725/

12. Volobueva A, Zhang D, Grechko A v., Orekhov AN. Foam cell formation and cholesterol trafficking and metabolism disturbances in atherosclerosis. Cor et Vasa. 2019;61(1):E48-E54. doi:10.1016/j. crvasa.2018.06.006 available from: https://www.sciencedirect. com/science/article/abs/pii/S0010865018300560
13. Chistiakov DA, Melnichenko AA, Myasoedova VA, Grechko A v, Orekhov AN. Mechanisms of foam cell formation in atherosclerosis. Journal of molecular medicine (Berlin, Germany). 2017;95(11):11531165. doi:10.1007/s00109-017-1575-8 available from: https:// pubmed.ncbi.nlm.nih.gov/28785870/

14. Kzhyshkowska J, Neyen C, Gordon S. Role of macrophage scavenger receptors in atherosclerosis. Immunobiology. 2012;217(5):492-502. doi:10.1016/j.imbio.2012.02.015 available from: https://pubmed. ncbi.nlm.nih.gov/22437077/

15. Nuhu AA. Bioactive Micronutrients in Coffee: Recent Analytica Approaches for Characterization and Quantification. ISRN Nutrition. 2014;2014:1-13. doi:10.1155/2014/384230 https://pubmed.ncbi. nlm.nih.gov/24967266/

16. Lorenzo JM, Munekata PES. Phenolic compounds of green tea: Health benefits and technological application in food. Asian Pacific Journal of Tropical Biomedicine. 2016;6(8):709-719. doi:10.1016/j. apjtb.2016.06.010 available from: https://www.sciencedirect.com/ science/article/pii/S2221169116300272

17. Daina A, Zoete V. A BOILED-Egg To Predict Gastrointestina Absorption and Brain Penetration of Small Molecules. ChemMedChem. Published online 2016:1117-1121. doi:10.1002/ cmdc.201600182 available from: https://pubmed.ncbi.nlm.nih. gov/27218427/

18. Parasuraman S. Prediction of activity spectra for substances Journal of Pharmacology and Pharmacotherapeutics. 2011;2(1):5253. doi:10.4103/0976-500X.77119 available from: https://pubmed. ncbi.nlm.nih.gov/21701651/

19. Lagunin A, Stepanchikova A, Filimonov D, Poroikov V PASS: Prediction of activity spectra for biologically active substances. Bioinformatics. 2000;16(8):747-748. doi:10.1093/ bioinformatics/16.8.747 available from: https://pubmed.ncbi.nlm. nih.gov/11099264/

20. Geloen A, Helin L, Geeraert B, Malaud E, Holvoet P, Marguerie G. CD36 inhibitors reduce postprandial hypertriglyceridemia and protect against diabetic dyslipidemia and atherosclerosis. PLoS ONE. 2012;7(5):1-12. doi:10.1371/journal.pone.0037633 available from: https://pubmed.ncbi.nlm.nih.gov/22662181/

21. Liu CH, Lee TH, Lin YS, Sung PS, Wei YC, Li YR. Pioglitazone and PPAR-ymodulating treatment in hypertensive and type 2 diabetic patients after ischemic stroke: A national cohort study. Cardiovascular Diabetology. 2020;19(1):1-13. doi:10.1186/ s12933-019-0979-x available from: https://pubmed.ncbi.nlm.nih. gov/31910836/

22. Rahaman SO, Zhou G, Silverstein RL. Vav protein guanine nucleotide exchange factor regulates CD36 protein-mediated macrophage foam cell formation via calcium and dynamin-dependent processes. Journal of Biological Chemistry. 2011;286(41):36011-36019. doi:10.1074/jbc.M111.265082 available from: https://pubmed.ncbi. nlm.nih.gov/21865158/

23. Park YM. CD36, a scavenger receptor implicated in atherosclerosis. Experimental and Molecular Medicine. 2014;46(6):1-7. doi:10.1038/ emm.2014.38 available from: https://pubmed.ncbi.nlm.nih. gov/24903227/

24. Zhao L, Varghese Z, Moorhead JF, Chen Y, Ruan XZ. CD36 and lipid metabolism in the evolution of atherosclerosis. British Medical Bulletin. 2018;126(1):101-112. doi:10.1093/bmb/ldy006 available from: https://academic.oup.com/bmb/article/126/1/101/4925499

25. Yuan S, Chan HCS, Hu Z. Using PyMOL as a platform for computational drug design. Wiley Interdisciplinary Reviews: Computational Molecular Science. 2017;7(2):1-10. doi:10.1002/wcms.1298 https://wires. onlinelibrary.wiley.com/doi/abs/10.1002/wcms.1298

26. Trott O, Olson AJ. AutoDock Vina: Improving the speed and accuracy of docking with a new scoring function, efficient optimization, and multithreading. Journal of Computational Chemistry. 2009;31(2):NANA. doi:10.1002/jcc.21334 available from: https://pubmed.ncbi. nlm.nih.gov/19499576/ 
27. Ferreira LG, dos Santos RN, Oliva G, Andricopulo AD. Molecular Docking and Structure-Based Drug Design Strategies. Vol 20.; 2015. doi:10.3390/molecules200713384 available from: https:// pubmed.ncbi.nlm.nih.gov/26205061/

28. Ramalakshmi K, Raghavan B. Caffeine in coffee: Its removal. Why and how? Critical Reviews in Food Science and Nutrition. 1999:39(5):441-456. doi:10.1080/10408699991279231 available from: https://pubmed.ncbi.nlm.nih.gov/10516914/

29. Vuong Q v., Golding JB, Stathopoulos CE, Nguyen MH, Roach PD. Optimizing conditions for the extraction of catechins from green tea using hot water. Journal of Separation Science. 2011;34(21):30993106. doi:10.1002/jssc.201000863 available from: https://pubmed. ncbi.nlm.nih.gov/21905216/

30. Fischer AG, Kummer PM. Process for decaffeinating raw coffee. 1993;(19):4. available from: https://patents.google.com/patent/ US5208056A/en

31. Liang $\mathrm{H}$, Liang $\mathrm{Y}$, Dong J, Lu J, Xu H, Wang $\mathrm{H}$. Decaffeination of fresh green tea leaf (Camellia sinensis) by hot water treatment. Food Chemistry. 2007;101(4):1451-1456. doi:10.1016/j. foodchem.2006.03.054 https://www.sciencedirect.com/science/ article/abs/pii/S0308814606002998

32. lanevski A, He L, Aittokallio T, Tang J. SynergyFinder: A web application for analyzing drug combination dose-response matrix data. Bioinformatics. 2017;33(15):2413-2415. doi:10.1093/ bioinformatics/btx162 available from: https://pubmed.ncbi.nlm.nih. gov/28379339/

33. Xu S, Huang $Y$, Xie $Y$, et al. Evaluation of foam cell formation in cultured macrophages: an improved method with Oil Red $\mathrm{O}$ staining and Dil-oxLDL uptake. Cytotechnology. 2010;62:473-481. doi:10.1007/s10616-010-9290-0 available from: https://pubmed. ncbi.nlm.nih.gov/21076992/
34. Temple JL, Bernard C, Lipshultz SE, Czachor JD, Westphal JA Mestre MA. The Safety of Ingested Caffeine: A Comprehensive Review. Frontiers in Psychiatry. 2017;8(May):1-19. doi:10.3389/ fpsyt.2017.00080 available from: https://www.ncbi.nlm.nih.gov/ pmc/articles/PMC5445139/

35. Wikoff D, Welsh BT, Henderson R, et al. Systematic review of the potential adverse effects of caffeine consumption in healthy adults, pregnant women, adolescents, and children. Food and Chemical Toxicology. 2017;109:585-648. doi:10.1016/j.fct.2017.04.002 available from: https://pubmed.ncbi.nlm.nih.gov/28438661/

36. Jung S, Kim MH, Park JH, Jeong Y, Ko KS. Cellular Antioxidant and Anti-Inflammatory Effects of Coffee Extracts with Different Roasting Levels. Journal of Medicinal Food. 2017;20(6):626-635. doi:10.1089/jmf.2017.3935 available from: https://europepmc.org/ article/med/28581877

37. Lagha A ben, Grenier D. Tea polyphenols inhibit the activation of NF$\mathrm{KB}$ and the secretion of cytokines and matrix metalloproteinases by macrophages stimulated with Fusobacterium nucleatum. Scientific Reports. 2016;6. doi:10.1038/srep34520 available from: https:// pubmed.ncbi.nlm.nih.gov/27694921/

38. Mao S, Wang K, Lei Y, Yao S, Lu B, Huang W. Antioxidant synergistic effects of Osmanthus fragrans flowers with green tea and their major contributed antioxidant compounds. Scientific Reports. 2017;7. doi:10.1038/SREP46501 available from: https:// www.nature.com/articles/srep46501

39. Kar NS, Ashraf MZ, Valiyaveettil M, Podrez EA. Mapping and characterization of the binding site for specific oxidized phospholipids and oxidized low density lipoprotein of scavenger receptor CD36. Journal of Biological Chemistry. 2008;283(13):87658771. doi:10.1074/jbc.M709195200 available from: https://pubmed. ncbi.nlm.nih.gov/18245080/

\section{GRAPHICAL ABSTRACT}

$$
1 \text { In silico study }
$$

ADME, biological function prediction and docking molecular of coffee and tea active ingredients with CD36 and PPARY

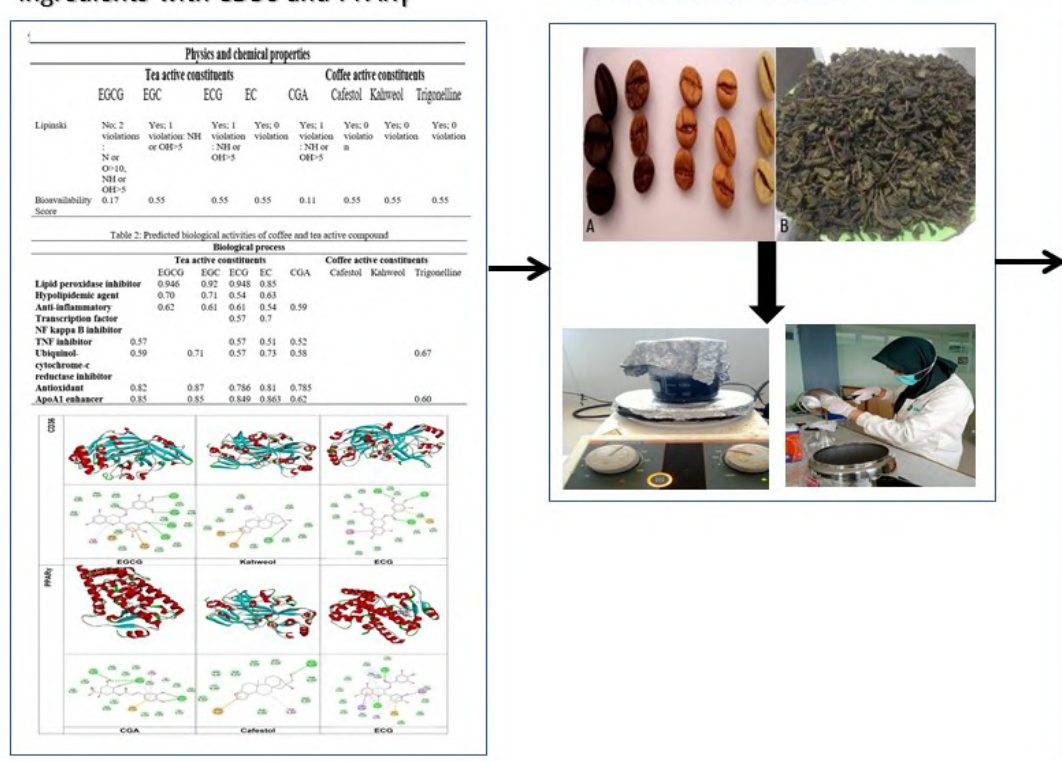

$$
3 \text { In vitro study }
$$

Coffee and green tea leaves preparation followed by Extraction Viability test to see the cytotoxicity effect of the single and combined extract, calculation of synergistic score and assessment of foam cell in oxLDL-stimulated Raw264.7 


\section{ABOUT AUTHORS}

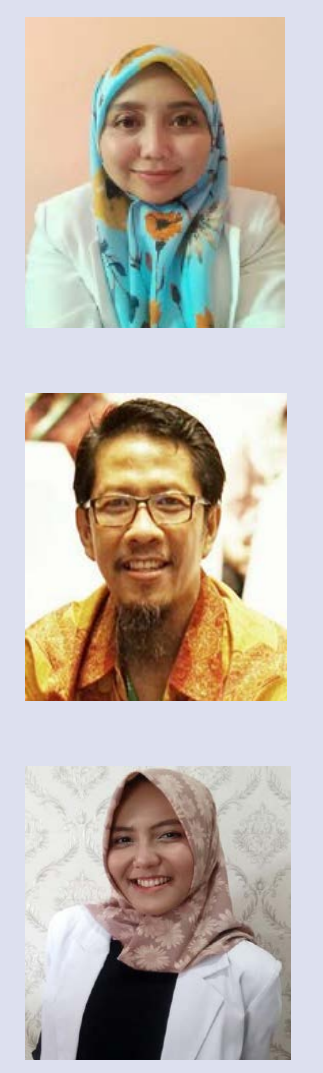

\section{Ermin Rachmawati}

Graduated from Faculty of Medicine Airlangga University as General Practitioner in 2006. In 2012, she completed her master degree from Brawijaya University. Now, she is taking her doctoral degree in Brawijaya University. She is a lecturer in Human Physiology Division Biomedical Science Department of Faculty of Medicine and Health Sciences, UIN Maulana Malik Ibrahim Malang. Her research is focusing in Metabolic and Cardiovascular Disease.

\section{Mohammad Saifur Rohman}

He completed his medical education as general practitioner from Airlangga University Indonesia in 1995. In 2004, he finished with his doctoral Program from Kobe University, Japan.. Beside his formal education, he also attended Fellowship of Interventional Cardiology, University of Indonesia, Fellow of International College of Angiology (FICA) in 2012, Fellowship of ASEAN College of Cardiology (FAsCC) in 2016, and Fellowship of The Society for Cardiovascular Angiography and Interventions (FSCAl) in 2018. He committed to clinical and biomedicine research majoring cardiovascular topic by become the pioneer of Brawijaya Cardiovascular Research Centre. He has published many articles in reputable journals.

\section{Lintang Widya Sishartami}

She graduated from Faculty of Medicine Brawijaya University in 2018 as general practitioner. Now, she is a student of Master Program in Biomedical Sciences Faculty of Medicine Brawijaya University.

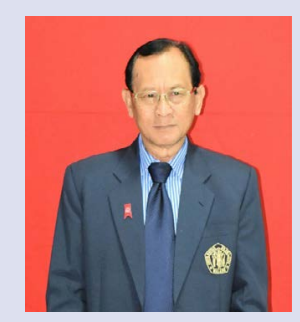

\section{Djanggan Sargowo}

Graduated from Medical Faculty of Universitas Gajah Mada as a General Practitioner, he then continued his study in Post Graduate Program in the field of Cardiovascular Medicine in Universitas Airlangga Surabaya. He was finished with his doctoral program in 1996. Besides formal education, he also attended Advanced Cardiology Course at The University of Hongkong in 1984, Senior Visiting Program at Institut Jantung Negara (IJN) of Kuala Lumpur in 1996, Fellowship of the American College of Cardiology (FACC) in 2006, Fellowship of the College Asia Pacific Society of Cardiology (FCAPC) in 2007, Fellowship of the European Society of Cardiology (FESC) in 2008 and Fellowship of the ASEAN College of Cardiology (FAsCC) in 2008. Board research expertise in: Biomedical and Atherosclerosis, Hypertension and Heart Failure, Small Cell Therapy: Stem Cell.

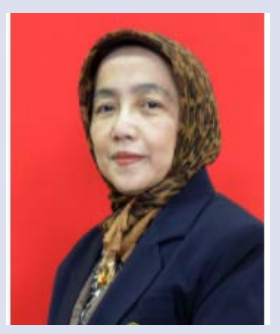

\section{Umi Kalsum}

She has graduated as physician from Brawijaya University in 1985. She pursued to take master degree and finished it in 1994 from Airlangga University in 1994. She completed her doctoral degree from Brawijaya University in 2004. She is now an active lecturer in Pharmacology Department of Faculty of Medicine Universitas Brawijaya. She also continuously doing research related to metabolic diseases.

Cite this article: Rachmawati E, Rohman MS, Sishartami LW, Sargowo D, Kalsum U. In Silico Modelling, Regulation of Cell Viability and Anti Atherosclerotic Effect in Macrophage by Decaffeinated Coffee and Green Tea Extract. Pharmacogn J. 2022;14(1): 46-55. 